\title{
OPEN Expression of purinergic receptors on microglia in the animal model of choroidal neovascularisation
}

\begin{abstract}
Lu Li ${ }^{1 凶}$, Juejun Liu ${ }^{1}$, Amin Xu$^{1}$, Peter Heiduschka ${ }^{2}$, Nicole Eter $^{2}$ \& Changzheng Chen ${ }^{1}$
To investigate the effect of $\mathrm{P} 2$ receptor on microglia and its inhibitor PPADS on choroidal neovascularization. Forty $\mathrm{CX} 3 \mathrm{CR} 1^{\mathrm{GFP} /+}$ mice were randomly divided into 8 groups. In addition to the normal group, the rest of groups were receiving laser treatment. The retina and choroid from the second, third, fourth and fifth group of mice were taken in the 1, 4, 7, 14 days after laser treatment. The mice in the sixth and seventh group received intravitreal injection of $2 \mu$ I PPADS or PBS respectively immediately after laser treatment. The mice in the eighth group received topical application of PPADS once per day of three days. The mice in sixth, seventh and eighth group received AF and FFA examination on the fourth day after laser treatment. Immunofluorescence histochemical staining and real-time quantitative PCR were used to evaluate P2 expression and its effect on choroidal neovascularization. After laser treatment, activated microglia can express $\mathrm{P} 2$ receptors (P2X4, P2X7, P2Y2 and P2Y12). The expression of P2 increased on the first day after laser damage, peaked on the fourth day $\left(t_{P 2 \times 4}=6.05, t_{P 2 X 7}=2.95, t_{P 2 Y 2}=3.67, t_{P 2 Y 12}=5.98\right.$, all $\left.P<0.01\right)$, and then decreased. After PPADS inhibition, compared with the PBS injection group, the mRNA of P2X4, P2X7, $P 2 Y 2$ and P2Y12 were decreased significantly in the PPADS injection group $\left(t_{P 2 \times 4}=5.54, t_{P 2 \times 7}=9.82\right.$, $t_{\mathrm{P} 2 \mathrm{Y} 2}=3.86, t_{\mathrm{P} 2 \mathrm{Y} 12}=7.91$, all $\left.\mathrm{P}<0.01\right)$ and the PPADS topical application group $\left(t_{\mathrm{P} 2 \times 4}=3.24, t_{\mathrm{P} 2 \times 7}=5.89\right.$, $t_{P 2 Y 2}=6.75, t_{P 2 Y 12}=4.97$, all $P<0.01$ ). Compared with the PBS injection group, not only the activity of microglia cells but also the leakage of CNV decreased significantly $(P<0.01)$ in the PPADS injection group and the PPADS topical application group. But between two PPADS groups, the leakage of CNV had no difference $(P=0.864)$. After laser induced $C N V$, activated microglia can express $P 2$ receptors. The $P 2$ receptor inhibitor, PPADS, can significantly affect the function of microglia and inhibit the formation of choroidal neovascularization.
\end{abstract}

Choroidal neovascularisation (CNV) is the complication of many ocular fundus diseases, such as wet age-related macular degeneration (wAMD), pathologic myopia (PM), punctate inner choroidal angiopathy (PIC), choroidal rupture, etc. It represents the leading cause of irreversible blindness or low vision in developed countries ${ }^{1}$. Numerous researches are likely to predispose an individual to CNV, which is considered an extremely complex, multifactorial disease, but the definite pathogenesis of CNV remains unclear.

Retinal microglia are resident immune cells in the retina. Distributed in a regular array throughout the inner retina, retinal microglial cells, through their dynamic process movements, carry out constant and dynamic immune surveillance of the extracellular environment and can respond rapidly to tissue injury by altering their activation state, acquiring capabilities of migration and proliferation, as well as secreting inflammatory mediators and neurotrophic agents ${ }^{2}$. Found throughout the central nervous system (CNS), microglia are capable of carrying out diverse sets of housekeeping functions under normal conditions and also executing adaptive functions under conditions of tissue injury ${ }^{3}$. A lot of studies reported that microglial cells play important roles in the physiological process of aging retina and pathological process of retina from wAMD patients and animal models $\mathrm{s}^{4,5}$.

Many questions still remain that what the exact function of microglia in pathogenesis of CNV and how it changes its behaviour in the diseased retina compared to a healthy one. Purinergic (P2) receptor, one of receptors on the microglial cells, has already been confirmed to be of critical importance for microglial cells in the $\mathrm{CNS}^{6-8}$. P2 receptors also exist on the microglial cells in the retina. However, some further investigations are still needed to confirm whether the inhibition of $\mathrm{P} 2$ receptors can influence the behaviour of microglial cells or change the pathological situation of $\mathrm{CNV}$ formation. In this study, we used the established experimental

\footnotetext{
${ }^{1}$ Department of Ophthalmology, Renmin Hospital of Wuhan University, 238 Jiefang Road, Wuhan, Hubei Province 430060, People's Republic of China. ${ }^{2}$ Department of Ophthalmology, University of Münster Medical

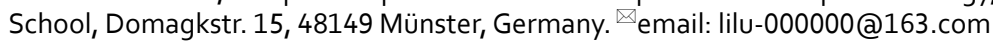




\begin{tabular}{|l|l|l|l|l|l|l|l|l|}
\hline Groups & 1st group & 2nd group & 3rd group & 4th group & 5th group & 6th group & 7th group & 8th group \\
\hline & (Normal group) & (Day 1 group) & (Day 4 group) & (Day 7 group) & (Day 14 group) & (PPADS inj. group) & (PBS inj. group) & (PPADS topical application group) \\
\hline Laser & No & Laser & Laser & Laser & Laser & Laser & Laser & Laser \\
\hline Treatment & No & No & No & No & No & PPADS inj & PBS inj & PPADS eye drops \\
\hline Day 1 & TS & TS & & & & & & PPADS eye drops \\
\hline Day 2 & & & & & & & & PPADS eye drops \\
\hline Day 3 & & & & & & & TSADS eye drops \\
\hline Day 4 & & & TS & & & & TS & TS \\
\hline Day 7 & & & & TS & & & & \\
\hline Day 14 & & & & & & & & \\
\hline
\end{tabular}

Table 1. The specific treatment approach of each group. TS take samples.

model of laser-induced CNV in mice. After treatment with a laser, CNV and tissue proliferation occur in the laser spots. It has been shown that microglia were accumulating in the laser spots ${ }^{9}$. For the activated microglial cells in the laser spot, we studied whether there were P2 receptors expressed by microglial cells, and whether PPADS (pyridoxalphosphate-6-azopheny 1-2',4'-disulfonic acid), a P2 antagonist, could influence the behaviour of microglia and have effect on the CNV.

\section{Materials and methods}

Animals. 40 six to eight weeks old $\mathrm{CX} 3 \mathrm{CR} 1^{\mathrm{GFP} /+}$ mice were used in this experiment, and all mice were bred and kept under IVC conditions. The CX3CR1 $1^{\mathrm{GFP} /+}$ mice were supplied by Prof. Heiduschka who was also the fourth author in this manuscript. The mice were divided into 8 groups randomly. There were five mice in each group, which included two or three female mice. This research followed the local animal ethics procedures and was approved by the ethics committee of Renmin Hospital of Wuhan University and University of Münster Medical School. All experiments were performed in accordance with the ARVO Statement for the Use of Animals in Ophthalmic and Vision Research and the EU directive 2010/63/EU. This study was carried out in compliance with the ARRIVE guidelines.

Mouse model of laser-induced CNV. Except for the normal group without any treatment (5 mice), the mice in the other 7 groups were receiving laser treatment. Mice were firstly anaesthetised by an intraperitoneal injection of a mixture of $130 \mathrm{mg} / \mathrm{kg}$ ketamine and $2.7 \mathrm{mg} / \mathrm{kg}$ xylazine. The pupils of mice were fully dilated with $1 \%$ tropicamide eye drops and 5\% neosynephrine eye drops. Before placed in front of the slit lamp for laser treatment, the cornea of mice was anaesthetised with $0.5 \%$ proparacaine eye drops. Both eyes of mouse were treated with a $532 \mathrm{~nm}$ argon green laser (NIDEK MC-500 Vixi, Nidek Co., Ltd. Gamagori, Japan) through dilated pupils with a coverslip over the cornea to create breaks in Bruch's membrane with a central bubble formation. The laser spots were placed on the retina around the optic nerve head between the large vessels. There were 7 laser spots in each eye. The laser beam had a diameter of $75 \mu \mathrm{m}$, duration of $100 \mathrm{~ms}$ and energy of $200 \mathrm{~mW}$.

Grouping and intervention. The first group is the normal group without any treatment. The specific treatment approach of each group can be referred to Table 1. After treated with a laser to induce CNV, animals in the second, third, fourth and fifth group received no subsequent treatment, and eyes were isolated at 1, 4, 7 and 14 days after laser treatment. Mice in the sixth, seventh and eighth group received intravitreal injection of $2 \mu \mathrm{l}$ PPADS (sc-202770A, Santa Cruz Biotechnology) (PPADS injection group) or phosphate buffered saline (PBS) (PBS injection group) immediately after laser treatment or eye drops of PPADS (PPADS topical application group) once per day after laser treatment until the third day, respectively. For intravitreal injections, a $1 \mathrm{~mm}$ aperture was made posterior to the superotemporal limbus with a sharp 30-gauge needle (Hamilton, Switzerland). Then a blunt 32-gauge needle (Hamilton, Switzerland) was inserted through this opening, and PPADS solution or PBS was injected slowly. The needle was left inside the eye for additional 3-4 s to minimise reflux and to allow for diffusion of the liquid. At 4 days after laser treatment, mice in PPADS injection group, PBS injection group and PPADS topical application group received scanning laser ophthalmoscopy examination. Then eyes were isolated to prepare cryosections for immunohistochemistry and PCR. For each mouse in all groups, one isolated eye was randomly selected for immunohistochemical staining, and the other eye for PCR detection.

Scanning laser ophthalmoscopy. Before examinations, mice were anaesthetised and pupils were dilated by the method described before. Green fluorescent protein (GFP) fluorescence and fluorescein angiography (FA) were performed with Heidelberg Retina Angiograph II from Heidelberg Engineering (Heidelberg, Germany). Fluorescein sodium ( $2 \mathrm{mg} / \mathrm{kg}$, Pfaltz \& Bauer, Waterbury, CT, USA) were delivered into mice by intraperitoneal injection. Immediately after injection, infrared reflectance recordings of the mouse retina were detected with a diode laser source of $815 \mathrm{~nm}$ wavelength. For GFP fluorescence imaging, an optically pumped solid state laser (OPSL) source was used to generate a blue light excitation wavelength of $488 \mathrm{~nm}$. Emitted light was detected between 500 and $700 \mathrm{~nm}$ with a detection efficiency of $85 \%$ for the fluorescence images. In FA images, the presence of an increasing hyperfluorescent lesion at the site of laser spot was defined as leakage from CNV. The whole 


\begin{tabular}{|c|c|c|c|c|}
\hline Antibody & host & dilution & source & No \\
\hline \multicolumn{5}{|l|}{ Marker for microglia } \\
\hline Ibal & rabbit & $1: 500$ & Wako & 019-19741 \\
\hline \multicolumn{5}{|l|}{ Purinergic receptors } \\
\hline $\mathrm{P} 2 \mathrm{X} 4$ & goat & $1: 10$ & Santa Cruz Biotechnology & sc-15187 \\
\hline $\mathrm{P} 2 \mathrm{X} 7$ & goat & $1: 10$ & Santa Cruz Biotechnology & sc- 15200 \\
\hline $\mathrm{P} 2 \mathrm{Y} 2$ & rabbit & $1: 50$ & Santa Cruz Biotechnology & sc-20124 \\
\hline $\mathrm{P} 2 \mathrm{Y} 12$ & goat & $1: 10$ & Santa Cruz Biotechnology & sc- 27152 \\
\hline \multicolumn{5}{|l|}{ Secondary antibodies } \\
\hline Anti rabbit $\mathrm{Cy} 3$ & goat & $1: 200$ & Life technologies & A10520 \\
\hline Anti goat AlexaFluor 488 & donkey & $1: 200$ & Life technologies & A11055 \\
\hline Anti rabbit AF 488 & donkey & $1: 200$ & Jackson ImmunoResearch & $712,547,003$ \\
\hline
\end{tabular}

Table 2. Primary and secondary antibodies used in this study.

\begin{tabular}{|l|l|l|}
\hline Target & Primer sequence (5' - 3') & Length (bp) \\
\hline P2X4 & $\begin{array}{l}\text { Forward TGTCCCCAGGCTACAATTTC } \\
\text { Reverse GGCAGCTTTTTCTCCCTTCT }\end{array}$ & 373 \\
\hline P2X7 & $\begin{array}{l}\text { Forward CTTTTGCACCTTGAGCTTCC } \\
\text { Reverse TCCATGCTAAGGGATTCTGG }\end{array}$ & 152 \\
\hline P2Y2 & $\begin{array}{l}\text { Forward GTGGCCTACAGCTTGGTCAT } \\
\text { Reverse GCGTGCGGAAGGAGTAGTAG }\end{array}$ & 235 \\
\hline P2Y12 & $\begin{array}{l}\text { Forward AGTGATGCCAAACTGGGAAC } \\
\text { Reverse TGAATGCCCAGATAACCACA }\end{array}$ & 208 \\
\hline
\end{tabular}

Table 3. Primer sequences for PCR analysis.

procedure of examination took approximate eight minutes after intraperitoneal injection of fluorescein. In order to improve the signal-to-noise ratio of the fluorescence signal, a mean image was calculated from several images using suitable image-analysis software (Heidelberg Eye Explorer, Heidelberg Engineering).

Eye cryosections. Mice were killed by cervical dislocation. Eyes were isolated, embedded in Tissue-Tek and immediately frozen in liquid nitrogen. Sections of $10 \mu \mathrm{m}$ thickness were made using a cryostat, mounted on glass slides and stored at $-20^{\circ} \mathrm{C}$ until further use.

Immunohistochemistry. Before staining, cryosection slides were dipped in $-20{ }^{\circ} \mathrm{C}$ cold methanol for $10 \mathrm{~min}$ for fixation and antigen retrieval. After rinsing with PBS, sections were blocked using Power Block ${ }^{\mathrm{m}}$ reagent (HK085-5K, BioGenex) for $6 \mathrm{~min}$ and incubated overnight at $4{ }^{\circ} \mathrm{C}$ with primary antibodies. The sections were washed three times with $0.1 \mathrm{M}$ PBS and then incubated with two different appropriate secondary antibodies at 1:200 dilution for $1 \mathrm{~h}$ at room temperature at the same time. The nuclei were counterstained with DAPI (4'6'-diamidino-2-phenylondole dihydrochloride) for $8 \mathrm{~min}$ at room temperature. Finally, sections were washed and mounted under glass coverslip using mounting media. Both primary antibodies and secondary antibodies were diluted with $1 \%$ bovine serum albumin (BSA). A summary of all antibodies used was listed in Table 2. Negative controls were obtained by staining procedures that omitted the primary antibody. A fluorescence microscope (EVOS fl, Advanced Microscopy Group, USA) was used to acquire images.

Reverse transcription and real-time quantitative PCR. Total RNA was extracted from retina and choroid of eyes in eight groups using TRIzol reagent (Invitrogen) following the manufacturer's instructions. $2 \mu \mathrm{g}$ total RNA from each sample was reverse-transcribed to cDNA with Easy-Script First-Strand cDNA Synthesis SuperMix (TransGen Biotech). The gene-specific primers (SBS Genetech) were listed in Table 3. RT-PCR was performed using SYBR Green RT-PCR Master Mix (TransGen Biotech) according to the manufacturer's instruction. The GAPDH was set as the internal control gene in the animal and cellular experiments. The relative quan-

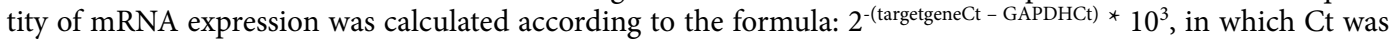
the threshold cycle number. All assays were repeated at least in triplicate independently. The RNA from different animals was measured individually.

Data analysis. Adobe Photoshop CS5 (Adobe, San Jose, CA) was used to quantify the leakage of fluorescence from CNV and the fluorescence of microglia in the laser spot by analysing the pixel intensity. Fluorescence ratio was calculated by comparing the pixel intensity of CNV or microglia in the laser spot with the pixel intensity of normal retina which was next to the laser spot. The statistical analysis was performed with ANOVA among PPADS intravitreal injection group, PPADS topical application group and PBS intravitreal injection 

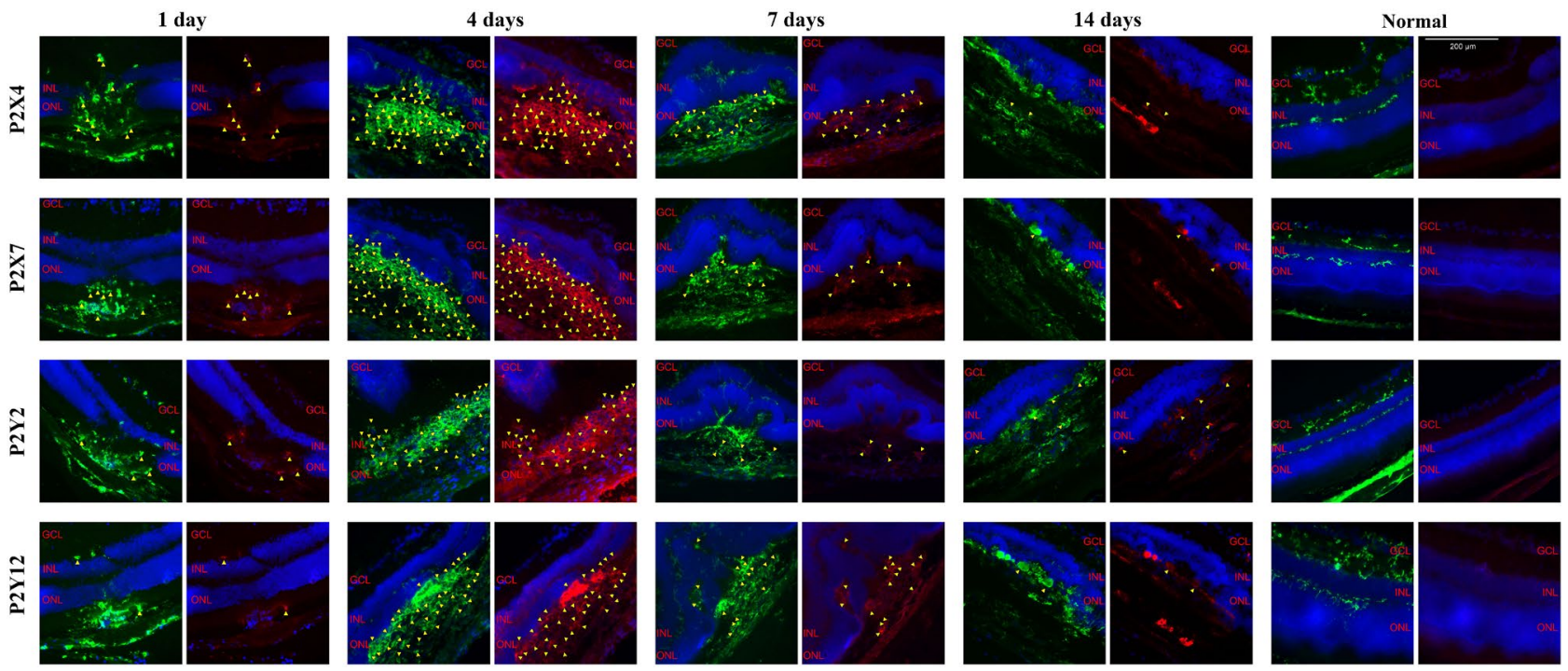

Figure 1. Cryosections of treated mouse eyes stained against Ibal (green) and P2 receptors (red) on different time points after laser treatment as indicated. The arrow showed the cells which were positive for Iba1 and P2 at the same time. Scale bar: $200 \mu \mathrm{m}$.

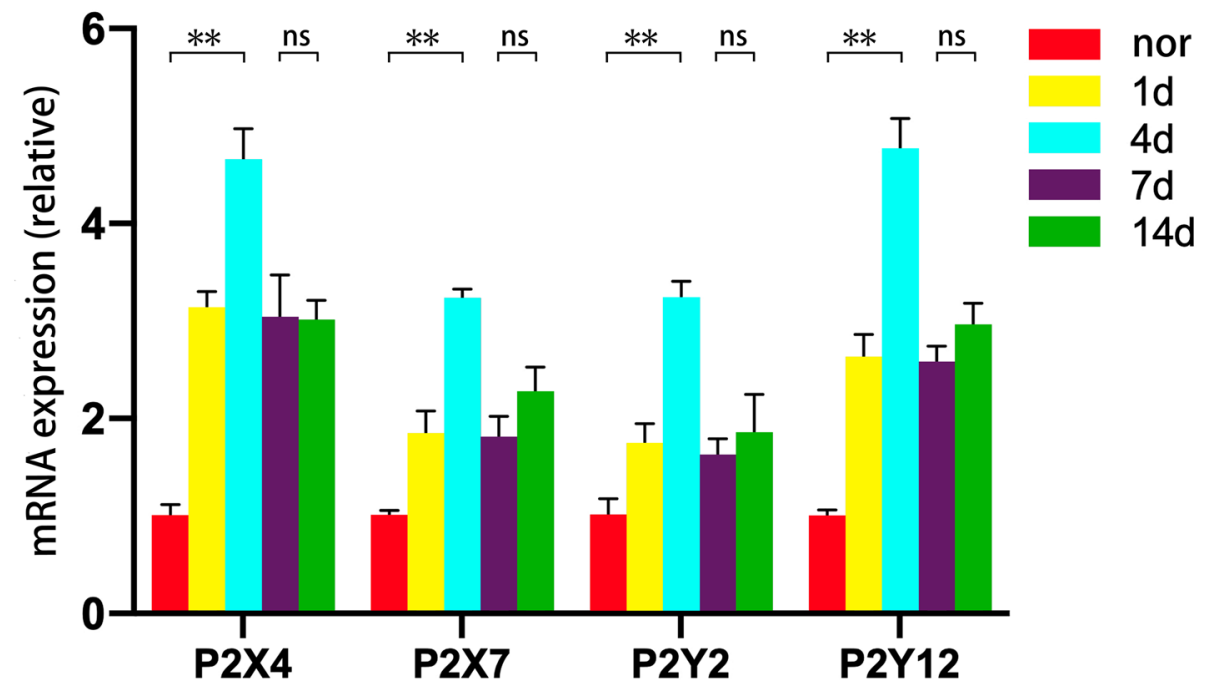

Figure 2. The expression level of $\mathrm{P} 2$ receptors' $\mathrm{mRNA}$ on different time points after laser treatment. $\left({ }^{* *} \mathrm{P}<0.01\right.$, ns (no significance) $\mathrm{P}>0.05$ ).

group using SPSS 19.0 software package (SPSS Inc., Chicago, IL, USA). A P value of $<0.05$ was considered statistically significant.

\section{Results}

Expression of purinergic receptors by microglia after laser treatment. The results of immunohistochemical double staining against Iba1 and purinergic receptors P2X4, P2X7, P2Y2 and P2Y12 at different time points after laser treatment were shown in Fig. 1. It was found that in the normal mouse retina, microglial cells showed almost no immunoreactivity for P2 receptors. After laser treatment, immunoreactivity for P2 receptors increased clearly, with the maximal response at day 4 after laser treatment. At day 14 after laser treatment, only several microglial cells showed immunoreactivity for $\mathrm{P} 2$ receptors.

The mRNA changing levels of $\mathrm{P} 2$ receptors were shown in Fig. 2. After laser treatment, mRNA of $\mathrm{P} 2$ receptors increased clearly at day 1 , with the maximal response at day $4\left(\mathrm{t}_{\mathrm{P} 2 \mathrm{X} 4}=6.05, \mathrm{t}_{\mathrm{P} 2 \mathrm{X} 7}=2.95, \mathrm{t}_{\mathrm{P} 2 \mathrm{Y} 2}=3.67, \mathrm{t}_{\mathrm{P} 2 \mathrm{Y} 12}=5.98\right.$, all $\mathrm{P}<0.01$, compared with the normal group), then declined. The expression levels between day 7 and day 14 had no significantly difference $\left(\mathrm{t}_{\mathrm{P} 2 \mathrm{X} 4}=9.59, \mathrm{P}=0.057 ; \mathrm{t}_{\mathrm{P} 2 \mathrm{X} 7}=11.32, \mathrm{P}=0.061 ; \mathrm{t}_{\mathrm{P} 2 \mathrm{Y} 2}=9.41, \mathrm{P}=0.064 ; \mathrm{t}_{\mathrm{P} 2 \mathrm{Y} 12}=6.97, \mathrm{P}=0.072\right)$.

The inhibition by PPADS on purinergic receptors and microglia. The results of immunohistochemical double staining against Ibal and P2 receptors after inhibition by PPADS showed that there were less micro- 

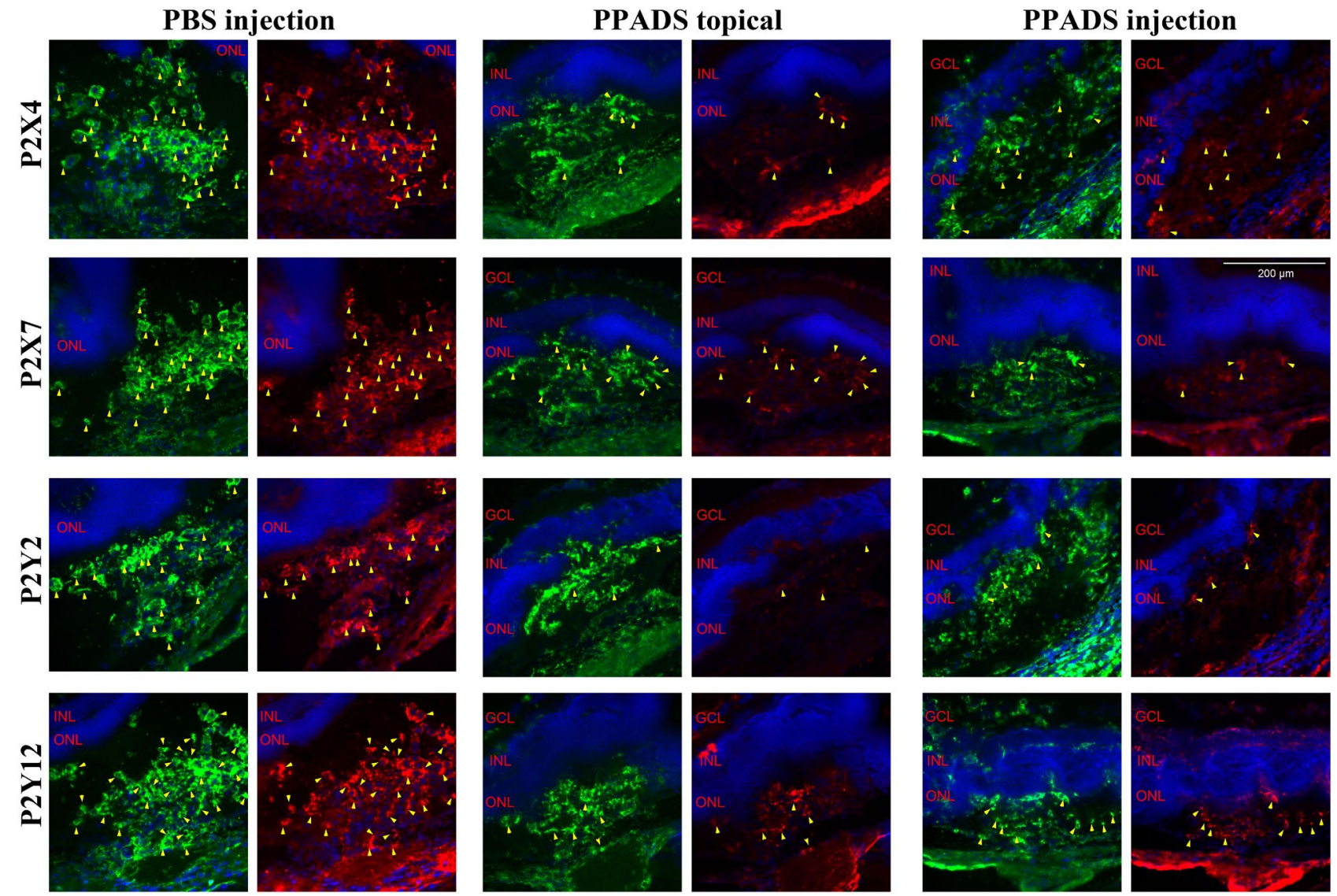

Figure 3. Double staining against Ibal (green) and P2 receptors (red) of cryosections obtained day 4 after laser and drug treatment as indicated. The arrow showed the cells which were positive for Iba1 and P2 at the same time. Scale bar: $200 \mu \mathrm{m}$.

glial cells positive for these four P2 recepors than PBS injection group, but the difference between PPADS topical application group and PPADS injection group was not very obvious. On staining pictures (Fig. 3), It was found that after treatment with PPADS, immunoreactivity for P2X4, P2X7 and P2Y2 was decreased clearly.

After PPADS inhibition, the mRNA changing levels of P2 receptors were shown in Fig. 4. Compared with PBS injection group, mRNA of P2 receptors decreased significantly both in PPADS topical application group $\left(\mathrm{t}_{\mathrm{P} 2 \mathrm{X} 4}=3.24, \mathrm{t}_{\mathrm{P} 2 \mathrm{X} 7}=5.89, \mathrm{t}_{\mathrm{P} 2 \mathrm{Y} 2}=6.75, \mathrm{t}_{\mathrm{P} 2 \mathrm{Y} 12}=4.97\right.$, all $\left.\mathrm{P}<0.01\right)$ and PPADS injection group $\left(\mathrm{t}_{\mathrm{P} 2 \mathrm{X} 4}=5.54, \mathrm{t}_{\mathrm{P} 2 \mathrm{X} 7}=9.82\right.$, $\mathrm{t}_{\mathrm{P} 2 \mathrm{Y} 2}=3.86, \mathrm{t}_{\mathrm{P} 2 \mathrm{Y} 12}=7.91$, all $\left.\mathrm{P}<0.01\right)$. Between different PPADS inhibition application groups, they had no differences $\left(\mathrm{t}_{\mathrm{P} 2 \mathrm{X} 4}=6.82, \mathrm{P}=0.876 ; \mathrm{t}_{\mathrm{P} 2 \mathrm{X} 7}=12.32, \mathrm{P}=0.793 ; \mathrm{t}_{\mathrm{P} 2 \mathrm{Y} 2}=10.13, \mathrm{P}=0.574 ; \mathrm{t}_{\mathrm{P} 2 \mathrm{Y} 12}=8.79, \mathrm{P}=0.497\right)$.

The leakage of fluorescence from CNV and the fluorescence of microglia after inhibition by PPADS. The mean fluorescence ratio of CNV in the PBS injection group was $2.38 \pm 1.35,1.55 \pm 0.54$ in the PPADS injection group, and $1.45 \pm 0.72$ in the PPADS topical application group. The ANOVA of the fluorescence ratio of CNV in these three groups was $12.53(\mathrm{P}<0.001)$. The mean fluorescence ratio of CNV in PPADS topical application group $(\mathrm{P}<0.001)$ and PPADS injection group $(\mathrm{P}<0.001)$ were significantly decreased compared with the mean fluorescence ratio of $\mathrm{CNV}$ in $\mathrm{PBS}$ injection group. The mean fluorescence ratio of $\mathrm{CNV}$ had no significantly difference between two PPADS inhibition groups $(\mathrm{P}=0.864)$ (Fig. 5).

The mean fluorescence ratio of microglial cells in the PBS injection group was $4.54 \pm 1.22,1.99 \pm 0.62$ in the PPADS injection group, and $2.74 \pm 0.84$ in the PPADS topical application group. The ANOVA of the fluorescence ratio of microglial cells in these three groups was $101.151(\mathrm{P}<0.001)$. The mean fluorescence ratio of microglial cells in PPADS topical application group $(\mathrm{P}<0.001)$ and PPADS injection group $(\mathrm{P}<0.001)$ were significantly decreased compared with the mean fluorescence ratio of microglial cells in PBS injection group. (Fig. 6).

\section{Discussion}

Purinergic receptors are a family of plasma membrane molecules in almost all mammalian tissues ${ }^{10}$. According to different activation, purinergic receptors included P1 receptors which response to the release of adenosine and $\mathrm{P} 2$ receptors which response to the release of adenosine triphosphate (ATP $)^{10}$. P2 receptors have two different subtypes, P2X and P2Y. P2X receptors (P2X1-P2X7) are coupled to non-selective cation channels, and P2Y receptors (P2Y1, P2Y2, P2Y4, P2Y6, P2Y11, P2Y12, P2Y13 and P2Y14) are G protein-coupled ${ }^{11}$. Inoue examined the microglia in a primary culture from rat brain and found that the microglia in the rat brain expresses mainly 


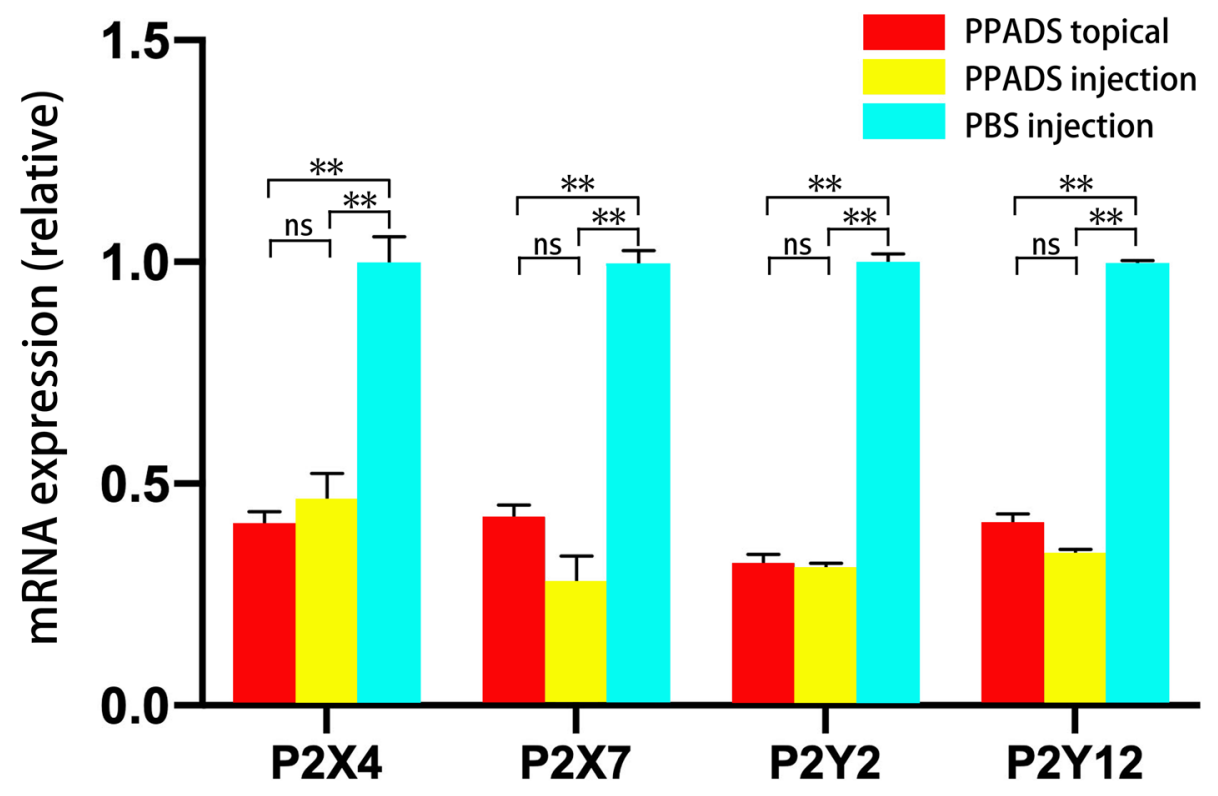

Figure 4. The expression level of $\mathrm{P} 2$ receptors' $\mathrm{mRNA}$ on Day 4 after laser and drug treatment. ${ }^{* *} \mathrm{P}<0.01$, ns $\mathrm{P}>0.05)$.

mRNAs of P2X4, P2X7, P2Y2, P2Y6 and P2Y12 ${ }^{11}$. In our study, we chose P2X4, P2X7, P2Y2 and P2Y12 as the main research targets, and found that these four purinergic receptors were also expressed on mouse retinal microglial cells.

$\mathrm{P} 2 \mathrm{X} 4$ receptor has been confirmed to have the physiological functions of modulation of neurotransmission and synaptic strengthening in the $\mathrm{CNS}^{12}$. In some studies, it is also reported that P2X4 receptors influence the inflammasome signalling after CNS injury ${ }^{13}$. Ho et al. studied the distribution of P2X4 receptors in the mouse retina using fluorescence immunohistochemistry and demonstrated that the staining of P2X4 receptors was colocalised with microglial cells ${ }^{14}$. Volonté et al. summarised the characteristic of P2X7 receptor and demonstrated that P2X7 can regulate the immune function and inflammatory responses as well as affect neuronal cell death in CNS and other systems ${ }^{15}$. Vessey and Fletcher performed immunohistochemical staining and concluded that in the mouse retina, microglial cells can express P2X7 receptors ${ }^{16}$. Gu et al. studied the relationship between $\mathrm{P} 2 \mathrm{X}$ and AMD in human blood and primate eyes and found that in AMD patients, the P2X4 Tyr315Cys variant was twofold more frequent than in age-matched control subjects, and the P2X7 Gly150Arg was also overrepresented in patients with $\mathrm{AMD}^{17}$. In primate eyes, both P2X4 and P2X7 receptors were detected on microglial cells immunohistochemically ${ }^{17}$. When these two receptors were unactivated, they can act as scavenger receptors in the eye to clear the debris and removal of subretinal deposits. Once activated, they may cause the loss of innate phagocytosis and predispose individuals towards $\mathrm{AMD}^{17}$. This conclusion was similar with our study that the expression of P2X4 and P2X7 was significantly high in laser-induced CNV model than in normal mice, which was a typical sign of wAMD.

P2Y2 and P2Y12 were reported to affect the activation and chemotaxis of microglia in brain ${ }^{18}$. Kobayashi et al. investigated the partial sciatic nerve ligation model in the rat and found that in the spinal cord, P2Y12 mRNA and protein increased dramatically and peaked at day 4 after injured ${ }^{19}$. They also confirmed that the cells expressing increased P2Y12 after nerve injury were exclusively microglia ${ }^{19}$. The response time and the source of P2Y12 in our research were in accordance with this finding. However, about the expression of P2Y2 and P2Y12 receptors on microglial cells in the retina in physiological or pathological conditions, limited information can be consulted. In the laser-induced CNV mouse model we applied in our study, the expression of P2Y2 and P2Y12 on microglial cells increased and reached the peak at day 4 after laser treatment. At different time points we checked, most of P2Y2 and P2Y12 receptors were expressed by microglial cells, especially at day 1 and day 4 after treatment.

We confirmed the expression of P2X and P2Y receptors on microglial cells in the animal model of laserinduced CNV. In our study, in the normal mouse retina, there were no microglial cells express P2X4, P2X7, P2Y2 and $\mathrm{P} 2 \mathrm{Y} 12$ receptors. After laser treatment, microglial cells express these four purinergic receptors, especially at day 4 after treatment. The decrease of the expression at day 7 and particularly at day 14 after laser treatment can possibly be attributed to a gradual decline of activation of microglial cells after their initial activation due to the damage elicited by the laser treatment ${ }^{20}$.

PPADS is an antagonist of purinergic receptors ${ }^{21}$. Sarman et al. found that PPADS can strongly inhibite the oxygen-induced preretinal neovascularization, and this was accompanied by a down-regulation of P2X2 receptor expression in the inner plexiform layer of mice ${ }^{22}$. Birke et al. studied laser-induced CNV mice models and performed topical application of PPADS on mice eyes for 3 consecutive days ${ }^{23}$. They found that PPADS can attenuate the area of $\mathrm{CNV}$ as well as the migration of endothelial cells, and attributed this result to the inhibition by PPADS on the complement activation and the membrane attack complex (MAC) formation ${ }^{23}$. In our 

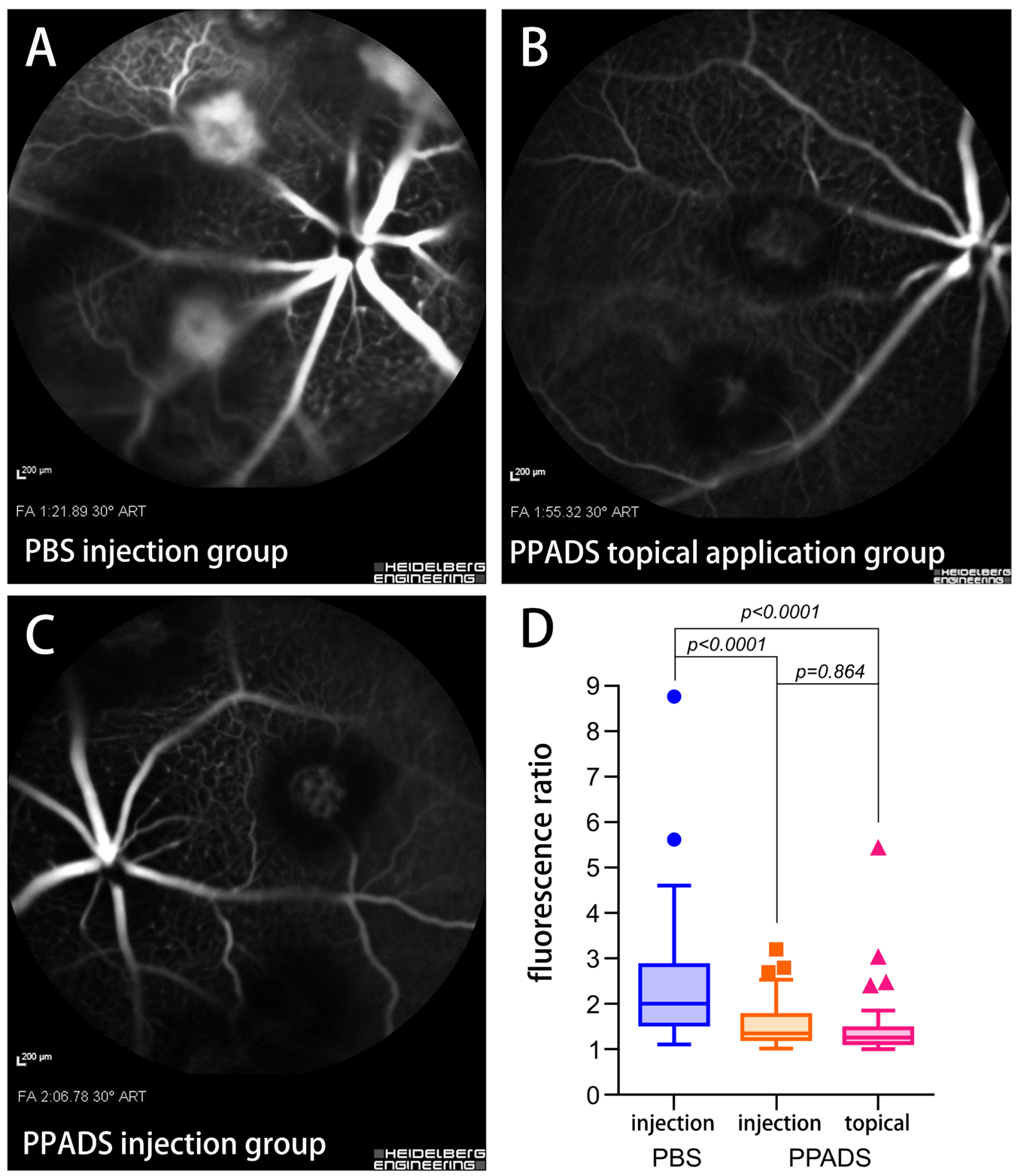

Figure 5. Representative fluorescein angiographs from the three experimental groups (A PBS injection group; B PPADS topical application group; C PPADS injection group) taken with the scanning laser ophthalmoscope. Diagram (D) shows results of numerical evaluation of intensity of fluorescence in the laser spots showing size of leakage.

research, we found the inhibition by PPADS not only on the reduced leakage of fluorescence from CNV, but also on the migration of microglial cells, demonstrated by reduced fluorescence in the area of the laser spot. We speculated that the inhibition by PPADS on the CNV may partly because that PPADS inhibited the P2 receptors on microglial cells, therefore inhibited the function of microglial cells which play critical roles in the pathological process of $\mathrm{CNV}^{4,20}$. Two different application ways of PPADS had no significant difference in inhibition of the leakage of fluorescence from CNV, but significant difference in the inhibition of the migration of microglia, 

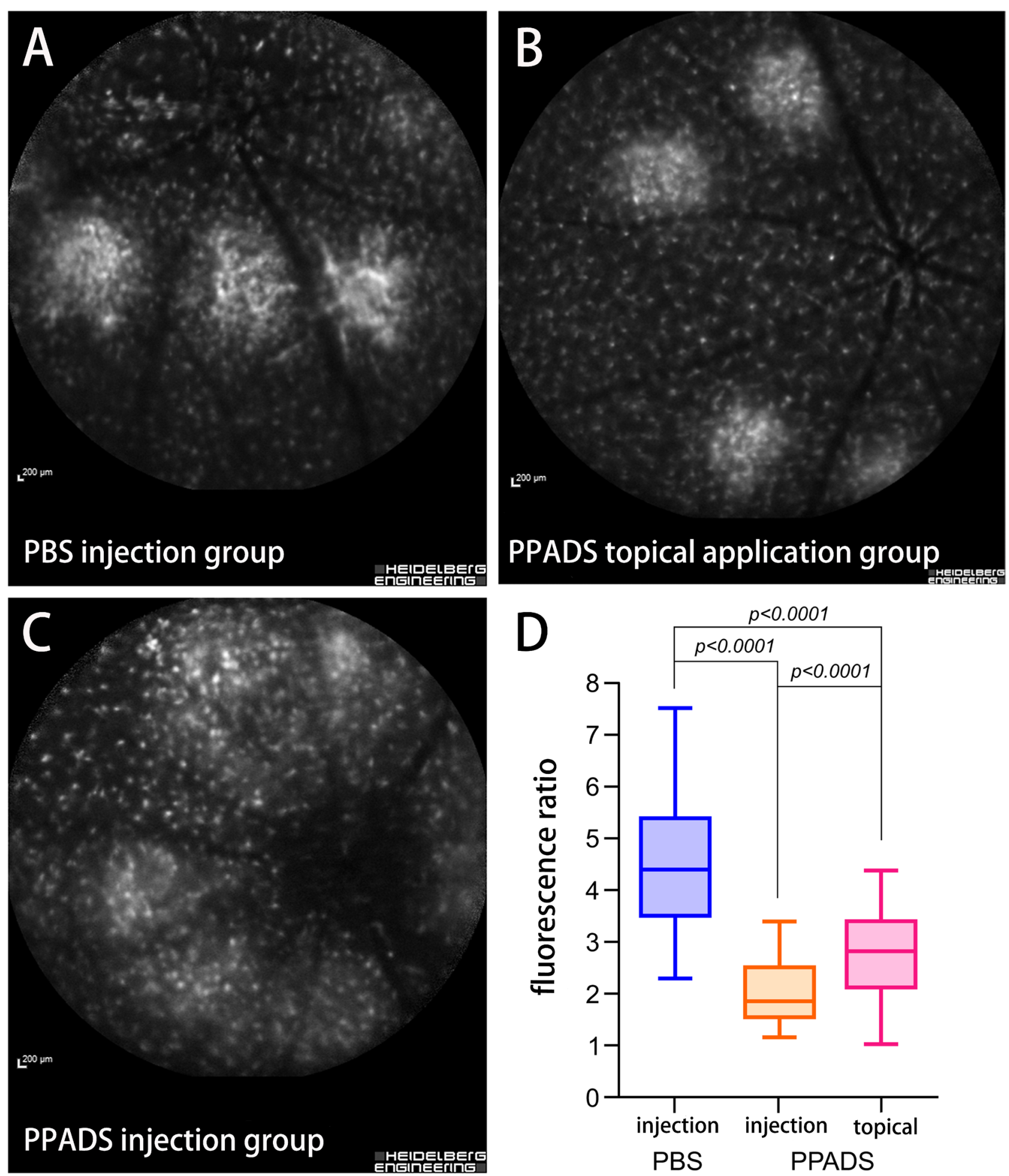

Figure 6. Representative images of GFP fluorescence of microglia in the laser spots in three experimental groups (A PBS injection group; B PPADS topical application group; C PPADS injection group) taken with the scanning laser ophthalmoscope. Diagram (D) shows results of numerical evaluation of intensity of fluorescence in the laser spots showing amounts of microglial cells that migrated into the laser spots.

which indicated that effective inhibition concentrations can also be achieved by eye drops. This offers the possibility of non-invasive treatment in the clinic study. However, in this study, we did not evaluate the potential differences of inhibited effect between topical application and intravitreal injection. Further study on the drug permeability and mechanism of action of PPADS may should be set in order to find the equivalent inhibition 
level. In addition, we preliminarily confirmed the inhibited effect of PPADS on CNV and microglia cells by giving PPADS intervention immediately after laser-induced CNV formation, but the differences of inhibition in different stages of CNV formation were not compared in this study. Based on this thinking, we are considering to study the inhibited effect of $\mathrm{P} 2$ receptors at more time points in order to obtain more valuable information to guide our further study of this project.

\section{Conclusion}

In our study, the microglial cells can express purinergic receptors P2X4, P2X7, P2Y2 and P2Y12 in the laser spots of mouse retina, especially at day 4 after treatment. The purinergic receptor inhibitor PPADS can significantly inhibit the formation of $\mathrm{CNV}$ and the migration of microglial cells both in topical application and intravitreal injection ways. Further research is needed to figure signalling pathways out in more details. Whether PPADS or other purinergic inhibitors can be used as a new therapy for $\mathrm{CNV}$, it still needs more research to investigate its safety and effectiveness.

\section{Data availability}

The data used to support the findings of this study are available from the corresponding author upon request.

Received: 12 February 2021; Accepted: 27 May 2021

Published online: 11 June 2021

\section{References}

1. Coleman, H. R., Chan, C. C., Ferris, F. L. 3rd. \& Chew, E. Y. Age-related macular degeneration. Lancet 372(9652), 1835-1845 (2008).

2. Hanisch, U. K. \& Kettenmann, H. Microglia: Active sensor and versatile effector cells in the normal and pathologic brain. Nat. Neurosci. 10(11), 1387-1394 (2007).

3. Ransohoff, R. M. \& Perry, V. H. Microglial physiology: Unique stimuli, specialized responses. Annu. Rev. Immunol. 27, 119-145 (2009).

4. Li, L., Eter, N. \& Heiduschka, P. The microglia in healthy and diseased retina. Exp. Eye Res. 136, 116-130 (2015).

5. Karlstetter, M. \& Langmann, T. Microglia in the aging retina. Adv. Exp. Med. Biol. 801, 207-212 (2014).

6. Sunkaria, A., Bhardwaj, S., Halder, A., Yadav, A. \& Sandhir, R. Migration and phagocytic ability of activated microglia during post-natal development is mediated by calcium-dependent purinergic signalling. Mol. Neurobiol. 53(2), 944-954 (2016).

7. Cheng, R. D., Ren, J. J., Zhang, Y. Y. \& Ye, X. M. P2X4 receptors expressed on microglial cells in post-ischemic inflammation of brain ischemic injury. Neurochem. Int. 67, 9-13 (2014).

8. Koizumi, S., Ohsawa, K., Inoue, K. \& Kohsaka, S. Purinergic receptors in microglia: Functional modal shifts of microglia mediated by P2 and P1 receptors. Glia 61(1), 47-54 (2013).

9. Eter, N. et al. In vivo visualization of dendritic cells, macrophages, and microglial cells responding to laser-induced damage in the fundus of the eye. Invest. Ophthalmol. Vis. Sci. 49(8), 3649-3658 (2008).

10. King, B. F. \& Burnstock, G. Purinergic receptors. In Understanding G Protein-Coupled Receptors and Their Role in the CNS (eds Pangalos, M. \& Davies, C.) 422-438 (Oxford University Press, 2002).

11. Inoue, K. Microglial activation by purines and pyrimidines. Glia 40(2), 156-163 (2002).

12. Baxter, A. W., Choi, S. J., Sim, J. A. \& North, R. A. Role of P2X4 receptors in synaptic strengthening in mouse CA1 hippocampal neurons. Eur. J. Neurosci. 34(2), 213-220 (2011).

13. de Rivero Vaccari, J. P. et al. P2X4 receptors influence inflammasome activation after spinal cord injury. J. Neurosci. 32(9), 30583066 (2012).

14. Ho, T., Vessey, K. A. \& Fletcher, E. L. Immunolocalization of the P2X4 receptor on neurons and glia in the mammalian retina. Neuroscience 277, 55-71 (2014).

15. Volonté, C., Apolloni, S., Skaper, S. D. \& Burnstock, G. P2X7 receptors: Channels, pores and more. CNS Neurol. Disord. Drug Targets 11(6), 705-721 (2014).

16. Vessey, K. A. \& Fletcher, E. L. Rod and cone pathway signalling is altered in the P2X7 receptor knock out mouse. PLoS ONE 7(1), e29990 (2012).

17. Gu, B. J. et al. A rare functional haplotype of the P2RX4 and P2RX7 genes leads to loss of innate phagocytosis and confers increased risk of age-related macular degeneration. FASEB J. 27(4), 1479-1487 (2013).

18. Kettenmann, H., Hanisch, U. K., Noda, M. \& Verkhratsky, A. Physiology of microglia. Physiol. Rev. 91(2), 461-453 (2011).

19. Kobayashi, K. et al. P2Y12 receptor upregulation in activated microglia is a gateway of p38 signaling and neuropathic pain. J. Neurosci. 28(11), 2892-2902 (2008).

20. Li, L., Heiduschka, P., Alex, A. F., Niekämper, D. \& Eter, N. Behaviour of CD11b-positive cells in an animal model of laser-induced choroidal neovascularisation. Ophthalmologica 237(1), 29-41 (2017).

21. Lambrecht, G. et al. PPADS, a novel functionally selective antagonist of P2 purinoceptor-mediated responses. Eur. J. Pharmacol. 217(2-3), 217-219 (1992).

22. Sarman, S. et al. Involvement of purinergic P2 receptors in experimental retinal neovascularization. Curr. Eye Res. 33(3), 285-291 (2008).

23. Birke, K., Lipo, E., Birke, M. T. \& Kumar-Singh, R. Topical application of PPADS inhibits complement activation and choroidal neovascularization in a model of age-related macular degeneration. PLoS ONE 8(10), e76766 (2013).

\section{Acknowledgements}

This work was supported by the grant No. 81600740 from The National Natural Science Foundation of China for L.L. and the grant No. 2042019kf0071 from the Independent Scientific Research of Wuhan University for L.L.

\section{Author contributions}

L.L. wrote the main manuscript. J.L. and A.X. prepared figures. P.H., N.E. and C.C. reviewed the manuscript.

\section{Competing interests}

The authors declare no competing interests. 


\section{Additional information}

Correspondence and requests for materials should be addressed to L.L.

Reprints and permissions information is available at www.nature.com/reprints.

Publisher's note Springer Nature remains neutral with regard to jurisdictional claims in published maps and institutional affiliations.

(c) (1) Open Access This article is licensed under a Creative Commons Attribution 4.0 International License, which permits use, sharing, adaptation, distribution and reproduction in any medium or format, as long as you give appropriate credit to the original author(s) and the source, provide a link to the Creative Commons licence, and indicate if changes were made. The images or other third party material in this article are included in the article's Creative Commons licence, unless indicated otherwise in a credit line to the material. If material is not included in the article's Creative Commons licence and your intended use is not permitted by statutory regulation or exceeds the permitted use, you will need to obtain permission directly from the copyright holder. To view a copy of this licence, visit http://creativecommons.org/licenses/by/4.0/.

(C) The Author(s) 2021 